\title{
Posicionalidades brujas: hacia un activismo de espiritualidad chicana/latina ${ }^{2}$
}

\author{
Bruja Positionalities: Toward a Chicana/Latina Spiritual Activism \\ Posicionalidades Bruxas: para um ativismo de espiritualidade chicana/latina
}

\begin{abstract}
Resumen
Este artículo de investigación profundiza sobre las construcciones de 'la Bruja' —una mujer practicante de conocimientos espirituales, sexuales y curativos- en nuestro imaginario cultural contemporáneo basado en el legado de la otrerización de curanderas en Europa y las Américas. En particular, analizo la canción “'Livin' La Vida Loca” de Ricky Martin sobre el poder ambivalente y hechicero que una mujer racializada ejerce sobre un hombre. Este artículo explora las maneras en que las 'brujas' son temidas por su conocimiento y poder, y por lo tanto, son sometidas a tratamientos opresivos. Mi planteamiento es por una posicionalidad bruja en los estudios feministas Chicana/Latina que incluya el desarrollo de nuestras propias epistemologías brujas. Como práctica de lo que Gloria Anzaldúa llamaría 'activismo espiritual', una posicionalidad bruja comprende curar las creencias internalizadas que demonizan la Bruja, la espiritualidad y sexualidad transgresivas que ella representa.
\end{abstract}

Palabras clave: estudios feministas, Chicana/Latina, activismo espiritual, posicionalidad bruja.

\section{Recibido: 21 de noviembre, evaluado: 8 de diciembre, aprobado: 9 de diciembre}

1 Profesora chicana asociada al Departamento de Estudios de la Mujer de la Universidad Estatal de San Diego en California. Activista espiritual con un doctorado en Estudios Étnicos, con énfasis en la mujer, género y sexualidad de la Universidad de California, Berkeley. Correo electronico: ilara@mail.sdsu.edu

2 Este es un artículo que fue publicado en inglés como "Bruja positionalities:Toward a Chicana/Latina Spiritual Activism" (2005) para la revista Chicana/ Latina Studies, 4(2), 10-45. Su traducción se publica con la gentil y expresa autorización de la autora. Este artículo es producto del trabajo de investigación desarrollado en el marco de una beca para adelantar estancia postdoctoral otorgada por la Fundación Ford.

Traducción especializada a cargo de Diana Carolina Pelaez Rodríguez, docente e investigadora del Centro de Educación para el Desarrollo y Max Schnuer, profesor de inglés en la Universidad del Rosario y traductor de literatura y humanidades, originario de Illinois, E.E...u., estudió pedagogía y escritura creativa en New School University en Nueva York.

Nota autora: Principalmente, estoy agradecida por la presencia de las obras y palabras de Gloria Anzaldúa en mi vida y en los cosmos. Esta guerrera cultural ha ya ha trascendido, pero sigue inspirándonos para ser activistas espirituales "sin armas, con los brazos abiertos, solo con nuestra magia" (1987). Además de la Fundación Ford por su generosa beca postdoctoral, mi agradecimiento se extiende a: Yolanda Venegas, Laura E. Pérez, Inés HernándezÁvila, AnaLouise Keating, Christina Grijalva, Laura Jiménez, KarenMary Davalos, y los revisores de la publicación Chicana/Latina Studies Journal por su comentarios constructivos en la concepción de este trabajo y de mi poema, Sarahi Núñez y Jessica Heredia por su ayuda en la investigación y a todas las mujeres con las que he tenido el honor de conversar y escuchar a lo largo de este proyecto, en su manifestación más amplia. Muchas gracias también a todas las otras personas que hacen posible y de modo agradable mi trabajo, incluyendo a mi pareja de vida Raúl, mi madre Dolores y mi segunda madre Edda, las cariñosas cuidadoras de mis hijas, a Belén y a Xóchitl. Esta meditación es para ellas y su generación. 


\begin{abstract}
This essay elaborates on constructions of "la Bruja" - a female practitioner of spiritual, sexual, and healing knowledges - in our contemporary cultural imaginary grounded in a legacy of the otherization of women healers in Europe and las Américas. Specifically, I analyze Ricky Martin's song “Livin' la Vida Loca” about the ambivalent witchy power of a racialized woman over a man. The essay explores the ways that "brujas" are feared for their knowledge and power and hence subjected to oppressive treatment. I argue a bruja positionality within Chicana/Latina studies that includes developing our own bruja-like epistemologies. As a practice of what Gloria Anzaldúa might call "spiritual activism," a bruja positionality is built on healing the internalized beliefs that demonize la Bruja and the transgressive spirituality and sexuality that she represents.
\end{abstract}

Keywords: Feminist Studies, Chicana/Latina, Spiritual Activism, Bruja Positionality.

\title{
Resumo
}

Este trabalho de pesquisa discorre sobre as construções da "Bruxa" - uma mulher praticante de conhecimentos espirituais, sexuais e curativos - em nosso imaginário cultural contemporâneo baseado no legado da otrerización (otredade) de curandeiras na Europa e as Américas. Especificamente, analiso a canção 'Livin' A Vida Louca' de Ricky Martin sobre o poder ambivalente e feiticeiro que uma mulher racializada exerce sobre um homem. Este artigo explora as maneiras em que as 'bruxas' são temidas por seu conhecimento e poder, e portanto, são submetidas a tratamentos opresivos. Minha proposta é por uma posicionalidade bruxa nos estudos feministas Chicana/Latina que inclua o desenvolvimento de nossas próprias epistemologías bruxas. Como prática do que Glória Anzaldúa chamaria 'ativismo espiritual', uma posicionalidade bruxa compreende curar as crenças internalizadas que demonizan a Bruxa, a espiritualidad e sexualidad transgresivas que ela representa.

Palavras-chave: estudos feministas, Chicana/Latina, ativismo espiritual, posicionalidade bruxa. 
Ostensiblemente, todas las mujeres en la época de la colonia en México y la América, como sus homólogas alrededor del mundo cristiano, eran sospechosas de ser brujas solo con base en su género, pero las mujeres de los grupos colonizados eran sospechosas por varios

motivos.

Mujeres indias, mujeres de origen africano y mujeres con mezclas raciales - fueran indo-mestizas o afro-mestizas - eran sospechosas por ser mujeres, por venir de culturas o religiones no cristianas o "diabólicas" y por ser gente colonizada o esclavizada que podría rebelarse y usar sus supuestos poderes mágicos en cualquier momento.

(Castañeda, 1998A)

Aqui estamos sin armas y con los brazos abiertos, solo con nuestra magia.

(ANZALdúA, 1987)

¿Es siempre sospechoso de que las mujeres de color $^{3}$ hagamos uso de nuestra magia? ;Bruja mala $a^{4}$ fue el escalofriante insulto que un conocido me dio cuando percibió que no estaba 'siguiendo las reglas' al encender la llama apasionada en él mientras bailábamos. ¡Bruja mala! fue su intento de disciplinarme de vuelta a la feminidad apropiada por expresar mi sexualidad y espiritualidad en mis propios términos. Tal acusación, en la Europa y las Américas de tiempos no tan lejanos, podría haber causado mi muerte por ahorcamiento, quema, ahogamiento u otras medidas tortuosas. ${ }^{5}$. En estos tiempos no vivía ni con mi padre, ni mi hermano o cualquier otro hombre, era económicamente independiente, aunque no adinerada, cuestionaba la autoridad de la jerarquía católica y del patriarcado en general, de vez en cuando practicaba la herbología y otras artes sanadoras sin certificado del Estado y participaba en otras actividades socialmente desestabilizantes. Todas esas cosas hubieran hecho aún más probable mi muerte ${ }^{6}$.

Como mínimo, considerar a una mujer como una bruja significaba el deseo por su muerte social, un intento por silenciar su cuerpomentespiri$t u^{7}$. Ciertamente, muchas de las acusadas fueron encarceladas, humilladas públicamente, exiliadas o marginadas de sus comunidades. Construirlas como mujeres intrínsecamente malvadas, servía a los intereses de la iglesia, el Estado y la familia patriarcales al hacerlas ejemplo de cómo no

3 En el campo feminista conocido como U.S. Third World Feminisms, el término "mujeres de color" o women of color es usado para expresar todas las experiencias femeninas racializadas dentro del contexto de los Estados Unidos, allí se incluyen comúnmente, pero no exclusivamente, a las mujeres negras, asiáticas, latinas, de medioriente y nativas americanas. (N. de T.).

4 Se dejan en cursivas las palabras que en el texto original en inglés han sido escritas en español. (N. de T.)

5 Durante la persecución europea en contra de las brujas, según estimaciones conservadoras, se mataron a miles de mujeres, pero según otras fuentes, se mataron varios millones. Anne Llewellyn Barstow sostiene que alrededor de unas 200,000 mujeres fueron acusadas de brujería y unas 100,000 fueron asesinadas. El sexo al que se dirigía la violencia era indiscutiblemente el femenino: alrededor del 85\% de las personas que ejecutaron "[... ] durante el mayor periodo de la caza de brujas (1560-1760)" eran mujeres (1994, p. 25). De acuerdo con las ideologías sexistas de ese tiempo, las mujeres eran inherentemente más susceptibles a la brujería por sus naturalezas supuestas "[... ] naturalezas lujuriosas. [...] débiles, frívolas, [y] maliciosas" (Nelson, 1975, p. 339). Tales representaciones de la mujer como "adoradoras del Diablo y malvadas" llegaron al continente americano y desde donde continuaron la conexión de las mujeres sanadoras con la maleficencia (Glass-Coffin, 1998, p. 36; Lavrin, 1989, p. 15). A pesar de esa violenta represión que experimentaron las mujeres indígenas y de otras mezclas raciales a comienzos del colonialismo español, la persecución vehemente contra las brujas experimentada en Europa nunca tuvo lugar en América; sin embargo, como documenta Antonia Castañeda, los oficiales de La Nueva España "[...] desestimaron, deslegitimaron, exiliaron 0 a veces ejecutaron a mujeres no blancas que eran acusadas de brujería", pues era tratada como transgresión religiosa y a menudo políitca (1998a, p. 237).

6 Según Barstow, la típica persona acusada de ser bruja en Europa era una mujer soltera , "[. . ] por lo tanto sospechosa en su comportamiento sexual", pobre, viuda, vieja, que se expresa sin tapujos y "[...] con el poder de curar, un poder que todos creían era también el poder de matar" (1994, pp. 16, 19, 27). Aunque la mayoría de las acusadas eran pobres, muchas también eran independientes económicamente y no se apoyaban en la estructura familiar tradicional patriarcal del medioevo para sobrevivir.

7 He formulado este concepto en conjunto para marcar y transformar las divisiones construidas entre el cuerpo, la mente y el espíritu que prevalecen en el pensamiento occidental. Tomó su forma del pensamiento indígena que ve el cuerpo, la mente y el espíritu como una conexión holística; el término representa al ser en su compleción. Véase Lara (2002). (N.de T: En el texto original se expone en inglés así “bodymindspirit” y se ha dejado en cursiva para identificar que es un neologismo de la autora). 
comportarse. Lamentablemente, más de siete siglos después del establecimiento de la Inquisición en el llamado Viejo Mundo y más de cuatro siglos después de su inauguración en el Nuevo Mundo, todavía se teme a las mujeres que ejercen su agencia espiritual y sexual y, por lo tanto, se les juzga, excluye y castiga ${ }^{8}$. Como muchas investigadoras feministas lo han documentado, las mujeres en el continente americano- como herederas de 'la Bruja', así como 'la malvada Eva,' 'la Malinche,' y otras figuras femeninas - seguimos siendo física y metafóricamente expulsadas del 'paraíso' por nuestro deseo de saber, hablar y practicar conocimiento transgresivo sobre la naturaleza, el espíritu y el erotismo?. Como una figura cultural femenina y empoderada, la Bruja simboliza un poder fuera del control del patriarcado que representa un potencial desafío al statu quo sexista. En las Américas, donde ha sido asociada con las creencias y prácticas 'supersticiosas' y 'primitivas' de las comunidades indias y afro-descendientes, la Bruja es también un personaje culturalmente racializado ${ }^{10}$. Muchas personas en las comunidades indígenas y chicanas/latinas no están cómodas con el término 'bruja', porque significa que es alguien que usa sus poderes para el mal. Para otras, es un símbolo positivo de la persistencia de conocimientos indígenas ${ }^{11}$, a pesar de los intentos por parte de la ciencia occidental ${ }^{12}$ y el colonialismo cristiano de destruirlos, invalidaros y apropiárselos.

Este artículo es parte de un proyecto mucho más amplio que se preocupa por descolonizar lo sagrado de las perspectivas opresivas cristianas y occidentales que perpetúan desconocimientos ${ }^{13}$, los cuales impactan en las vidas de las mujeres de maneras negativas ${ }^{14}$. Específicamente, me interesan las maneras en que las instituciones sociales han dicotomizado y colonizado el poder sexual y espiritual de las mujeres de color en las Américas,

8 A pesar de que la Inquisición se estableció a comienzos del siglo XIII en toda la Europa cristiana, no es hasta la emergencia de España como un estadonación que la Inquisición Española alcanzó su máxima expresión en 1478 (Blötzer, 2003; Giles, 1999). Como lo explica Castañeda, era una "[...] institución política espantosa designada para "limpiar" a España de las prácticas y creencias heréticas no cristianas". Más aún, "[m]ientras se enfocó en el judaísmo y el islam, la Inquisición también intentó abolir todo el 'paganismo' residual, en particular la brujería y la hechicería" (1998c, p. 638). Actividades inquisitoriales e informales en el hoy llamado México, comenzaron en 1522 poco después de la invasión española (Greenleaf, 1969). El primer obispo de Nueva España, Juan de Zumárraga, condujo 23 juicios de brujería y superstición entre 1536 y 1543. Los indios acusados fueron castigados por ser hechiceros, idólatras, profetas, fomentadores de rebelión (Behar, 1987b) y "probablemente" por practicar la medicina tradicional (Quezada, 1991). Aunque estos juicios iniciales involucraron solo a una mujer (Klor de Alva, 1991), muchas más mujeres fueron juzgadas en las décadas siguientes y a lo largo de la vida de la Inquisición Mexicana que formalmente empezó en 1571 y terminó en los primeros años del siglo XIX. En mi propio análisis de la investigación de Quezada (1991) sobre 71 curandero/as 'mexicanos' que fueron acusados de, por ejemplo, 'curar por encantamiento', por tomar 'peyote como ayuda adivinatoria' y por ser una 'curandera supersticiosa' o 'partera maleficente', 47 eran mujeres (66\%) (pp. 41-45).

9 Ana Castillo (1994), por ejemplo, discute el mito original de Eva de las culturas judeocristianos, muy poderoso socialmente y psicológicamente, y el mito mexica, menos conocido, de Xochiquetzal en donde ambas son construidas como las causantes de la 'caída' de la humanidad de un supuesto 'paraíso' (pp. 106-110). Gloria Anzaldúa también discute cómo "[...] en la búsqueda del conocimiento, incluso al conocimiento carnal. [...] [estas] figuras femeninas de origen 'desobedecieron"”. Por su desobediencia y por " [... ] comer la fruta del árbol del conocimiento del bien y el mal y por ejercer agencia individual [son] expulsados del 'paraíso'" (2002, p. 543). Sobre La Malinche como arquetipo de traidora y puta que vendió su pueblo indígena a los colonizadores, véase el clásico ensayo de Norma Alarcón, "Traddutora, Traditora: A Paradigmatic Figure of Chicana Feminism" (1989).

10 En un extenso estudio sobre casos de brujería sexual en el México colonial, Behar (1989) señala que el 'poder misterioso' le fue atribuido, en particular, a las "[...] mujeres de las castas marginales, indias y mezcladas" (p. 179). De los 71 casos anti-curandero/as que documentó Quezada (1991), todos fueron categorizados como indios, negros, mestizos/as, mulatos/as o castizos/as, menos once españoles y ochos personas no identificadas (73 por ciento). De estos 52 casos, la mayoría (31) eran mujeres racializadas (60 por ciento).

11 Uso el término 'conocimiento' [originalmente en español] que propuso Gloria Anzaldúa para significar comprensiones y modos de conocer, en particular conocimientos, sabiduría, conciencia, intuición, percepción o sensibilidad que no son legitimizados por las culturas dominantes (2000, pp. 177-78).

12 Uso deliberadamente 'western' [occidental] en letras minúsculas [en inglés se usa la mayúscula en la primera letra] para no reinscribir a 'occidente' como un espacio geopolítico privilegiado y monolítico.

13 'Desconocimiento' [originalmente en español] significa "[...] no conocer, por voluntad... [0] involuntariamente, por conveniencia" (Anzaldúa, 2000, p. 177).

14 El libro se llama Decolonizing the Sacred: Healing Practices on the Borderlands. 
y del mismo modo cómo estas mujeres descolonizan tales construcciones mediante prácticas curativas. Con el objetivo de entender las maneras complejas en que el patriarcado y el colonialismo afectan las subjetividades sexuales y espirituales racializadas. Mi investigación ${ }^{15}$ incluye un análisis del proceso de brujización. ¿Cuál es el legado cultural colonial del discurso sobre las brujas? ¿Por qué las mujeres racializadas, en este caso las latinas ${ }^{16}$, siguen siendo sometidas a este tropo misógino de la bruja? ¿Cómo resisten, apropian y transforman las latinas tal brujización?

Con preguntas tan vitales que atraviesan mis pensamientos, en este artículo me concentro primero en las construcciones de la Bruja - una mujer que practica saberes espirituales, sexuales y curativos enraizados en los conocimientos indígenas o mestizos - en nuestro imaginario cultural contemporáneo. Este imaginario se basa en un legado de otrerización de curanderas en Europa y las Américas ${ }^{17}$. Específicamente, analizo la canción de éxito internacional: “Livin' La Vida Loca” interpretada por Ricky Martin; y que trata sobre el aparente poder hechicero y ambivalente que una mujer racializada ejerce sobre un hombre. A lo largo de este artículo, recurro al pensamiento de Chicanas/Latinas ${ }^{18}$ y otras para explorar las maneras en que las brujas, o las mujeres que han sido percibidas así, son temidas por su conocimiento y poder y por los cuales han sido sometidas a tratamientos opresivos. Finalmente, propongo el desarrollo de una posicionalidad bruja dentro de los estudios feministas Chicana/Latina que incluya desarrollar nuestras propias epistemologías brujas en el proceso de re-memorar, revisar y construir conocimiento, así como la participación en otras formas de cambio social. Como práctica de lo que Gloria Anzaldúa ha llamado 'activismo espiritual', una posicionalidad bruja consiste en sanar los desconocimientos internalizados que demonizan a la Bruja y las espiritualidades y sexualidades transgresivas que ella representa ${ }^{19}$. Si realmente queremos promulgar una visión espiritual de interconexión entre todos los seres vivos, esto conlleva reclamar la Bruja interior y exterior, a pesar del miedo que su representación engendre en la cultura dominante. Además, nutrir la Bruja interna y externa hace parte de un cambio social que legitima los conocimientos espirituales y sexuales indígenas y mestizos y que, más adelante, puedan inspirar y facilitar más cambios sociales positivos.

\section{La Bruja en el imaginario cultural: ¿una dicotomía de bruja mala/ curandera buena?}

Muchas personas han internalizado una percepción de las brujas como malas, repugnantes, lujuriosas, locas, alborotadoras, causantes de enfermedades y destructoras (sea de huertas, animales o personas). Otra percepción relacionada es aquella de la bruja como practicante de magia sexual; alguien que sabe cómo, por ejemplo, atraer y 'atar' a un hombre en contra de su voluntad y causar impotencia (Behar, 1989; Quezada, 1975). Tales proyecciones

15 "Decolonizing Latina Spiritualities and Sexualities: Healing Practices in las Américas" (2003).

16 En Estados Unidos, el término 'Latino o Latina' se usa como identificación étnica con base en el territorio y se refiere a quien ha nacido o tiene ascendencia latinoamericana; identificarse como latino en ese contexto tiene propósitos políiticos de constituir una unidad, un eje común -sin borrar la gran diversidad cultural que ese territorio acoge - ante la cultura dominante (N. de T.).

17 Véase Barstow (1994) para un resumen histórico de cómo y por qué las sanadoras europeas eran redefinidas como brujas (pp. 109-27). Véase también Ehrenreich y English (1973) que discuten sobre el impacto de la ciencia y el ascenso de la medicina como una vocación masculina que continúa deslegitimando a las mujeres sanadoras.

18 Sobre los múltiples sentidos del uso de la barra entre 'Chicana' y 'Latina', véase Karen Mary Dávalos y Alicia Partnoy (2004).

19 Sobre Activismo espiritual, véase Anzaldúa (2000, p. 178); Anzaldúa (2002, pp. 568-74); Keating (2002) y Keating (2005). Como lo define AnaLouise Keating, "El activismo espiritual es una epistemologia y una etica visionaria con base en la experiencia, una forma de vida y un llamado a la acción. A nivel epistemológico, el activismo espiritual propone una metafísica de la interconexión y emplea modos no binarios de pensamiento. Al nivel ético, el activismo espiritual requiere acciones concretas diseñadas para intervenir en y transformar las condiciones sociales actuales. El activismo espiritual es espiritualidad para el cambio social, una espiritualidad que reconoce las muchas diferencias entre nosotros, pero insiste en lo que tenemos en común y usa estos valores comunes como catalizadores para la transformación social" (2005, p. 242). 
de los miedos de la sociedad, sin importar en qué medida estén basados en la realidad, siguen justificando el tratamiento opresivo de las brujas o las mujeres que parecen brujas. La creencia común de que las brujas son en esencia mujeres malas, o al contrario, que las mujeres malas son en esencia brujas, es un desconocimiento cuyas raíces están en el pensamiento patriarcal occidental de la Europa medieval y la América colonial, el cual ha construido generalmente a las mujeres como el sexo inferior ${ }^{20}$. Cuando no eran representadas en un modo opresivo como espiritualmente superiores a los hombres - es decir, la creencia de que las mujeres deben emular a la Virgen María como la madre sacrificada, devota y asexual-, los conocimientos espirituales, sexuales y curativos de las mujeres han sido significados negativamente como heréticos, supersticiosos, diabólicos y/o primitivos. Estas ideologías están relacionadas con la construcción de las mujeres como híper-espirituales y asexuales (o sexuales solo dentro de los límites de la heterosexualidad y el matrimonio) o como hechiceras (anti-espirituales) e híper-sexuales. En cuanto tal, reafirman el binario espiritual/sexual de género.

Además, muchas latinas indígenas, negras y mestizas han sufrido las consecuencias de esta separación, la cual ha sido y sigue siendo racializada (Castañeda, 1998a). Esta supuesta separación espiritual/sexual ha sido exacerbada por la necesidad que tiene Occidente de redefinirse y diferenciarse del 'Otro' del Nuevo Mundo después de 1492 (Todorov, 1999). De hecho, uno de los desconocimientos perpetuados después del encuentro colonial, o mejor aún, el encontronazo (Torres, 1998), era la demonización de las mujeres y las 'diosas' indígenas ${ }^{21}$. Tal violencia discursiva alrededor de las mujeres y figuras femeninas poderosas sexual y espiritualmente, justificaba el legado de violencia física y psicológica contra las mujeres en el continente americano, perpetuado principalmente por los colonizadores europeos, pero también por indígenas imperialistas, por ejemplo, los Aztecas. Como lo ha afirmado Antonia Castañeda:

En la mirada imperialista cristiana, las mujeres no cristianas y sus hijas mestizas eran sexualizadas, racializadas y demonizadas por el aparente crimen religioso de brujería; sin embargo, muchas veces eran juzgadas en cortes seculares, donde la brujería era considerada un crimen político. (1998a, p. 237).

Dada la representación tan negativa de la bruja racializada, no es de extrañar que de modo similar a la dicotomía virgen/puta que intenta regular la sexualidad latina sobre el eje de una perspectiva cristiana del mundo (Castillo, 1994), la dicotomía curandera buena/bruja mala se han desarrollado en un intento de dar orden a la espiritualidad no institucional. En este marco binario en el que prima el valor de la primera categoría sobre la última, las curanderas son sanadoras de-sexualizadas y las brujas practican la 'magia negra' y la 'brujería se$x^{x u a l}{ }^{22}$. En resistencia a este binario que muchas de nosotras hemos internalizado, Ana Castillo (1994) propone que tanto las brujas como las curanderas son valiosas sanadoras. La primera es una 'sanadora espiritual o psíquica', (p. 156) que puede “[...] comunicar con el mundo de los espíritus" (p. 157) y la segunda es una 'sanadora especializada', una sabia en distintas áreas de experticia médica, como, por ejemplo: hierbas medicinales (yerberas),

20 Las creencias sexistas dominantes en occidente sobre la inferioridad 'natural' de las mujeres pueden rastrearse en las articulaciones previas al cristianismo, judaísmo y la filosofía griega (Turner, 1997, pp. 24-25). Aunque mi enfoque en este artículo es el legado del pensamiento colonial occidental, también es importante considerar las construcciones negativas de lo femenino en los grupos indígenas.

21 Escribo 'diosa' entre comillas para señalar que este término occidental no describe adecuadamente a las figuras indígenas veneradas que simbolizan las fuerzas de la naturaleza.

22 Se debe reconocer que "la palabra 'curandero' no tiene un sentido exacto", Treviño (2001) lo define como "[..] una persona que cura 0 trata de curar, en concordancia con los patrones antiguos indígenas prehispánicos, agregándoles el conocimiento acumulado de casi cinco siglos desde la Conquista española" (p. 47). Las raíces híbridas del curanderismo, "[. . . de la palabra española 'cura' que significa 'sanar' o 'ser sacerdote" (Ávila, 1999, p. 16) incluyen medicina griega, árabe, judía sefardí, española, indígena y africana (pp. 22-35). Como Elena Ávila, una curandera chicana, lo señala, el curanderismo "[...] no separa el alma y el espíritu del cuerpo. Es medicina y espiritualidad que se practica simultáneamente" (p. 16). Además, "[...] es un sistema de salud con bases firmes en la tierra y lo natural que busca balancear todos los elementos de nuestro ser" (p. 19). 
masajes (sobadoras) o la partería (parteras). Ambas clases de sanadoras consideran que el cuerpo, la mente y el espíritu están integrados y “[...] consideran al enfermo en su totalidad” (p. 156).

Ciertamente, como lo señala Tey Diana Rebolledo (1995) en su análisis sobre el compromiso que las escritoras Chicanas sienten por 'la heroína arquetípica' de la curandera-bruja ${ }^{23}$, algunas de estas prácticas curativas existen en la misma sanadora, desdibujando asíl la distinción entre las dos. Así propone que "[...] la curandera es siempre también la bruja; es decir, tiene el poder de convertirse en una, pero es posible que nunca decida hacerlo" (p. 83). La atribución de características negativas a la bruja, como su habilidad de destruir, vengarse y 'controlar el otro nebuloso mundo' ha sido concebida desde la perspectiva cultural occidental del mundo. Rebolledo deja en claro que "[...] estos mismos atributos 'negativos' han sido incorporados por las culturas indias y populares como parte de su esencial ciclo de vida" (p. 83) ${ }^{24}$. Es interesante, cuando Rebolledo hace la conexión entre la curandera y la Virgen María, cómo su enfoque destaca las características 'positivas' de 'curación, sanación, ayuda' que ellas comparten y excluye la discusión sobre la sexualidad, un aspecto destacado en la figura 'virginal' de la María. Del mismo modo, en su discusión sobre cómo la curanderabruja “[...] representa más allá de su lado de ayudar y nutrir [...] como las deidades Nahuas, también la capacidad de muerte y destrucción" (p. 89); Rebolledo no explora las construcciones culturales que conectan a la Bruja con la magia sexual y con una libido poderosa, particularmente cuando se yuxtaponen a una figura de consideración más positiva como el de la curandera/Virgen María ${ }^{25}$. Sin embargo, citando a Anzaldúa, Rebolledo concluye su exploración con la lección máxima que ofrece el arquetipo de la curandera-bruja: "[...] para llegar a ser nosotras, en la mayor totalidad posible, debemos integrar las serpientes, lo <negativo> y aceptar el poder del autoconocimiento y la autoexpresión que conlleva" (p. 94).

La separación binaria entre las 'malas' brujas y las 'buenas' curanderas es precaria cuando se considera la fuerza que ha tenido la medicina occidental y las ciencias sociales en deslegitimarlas a ambas como prácticas no científicas y el poder que ha ejercido la iglesia institucional en sancionarlas a ambas como prácticas paganas $^{26}$. Al intentar validar los beneficios

23 Para significar la conexión entre la curandera y la bruja, uso un guion en lugar de una barra, como lo hace Rebolledo, para deconstruir visualmente el sentido de que forman un binario oposicional (a veces señalado con una barra). Las curanderas y brujas no solo pueden compartir conocimientos y habilidades similares, sino que también muchas veces se les ve y trata en modos similares (negativamente en su mayoría, desde las perspectivas culturales dominantes). Además, alterno curandera y bruja al principio en la escritura de la díada, para no privilegiar a una de las dos, y particularmente para oponerme a la 'bruja' históricamente demonizada, una palabra que sigue evocando miedo y odio racializado y generizado. Como indico en mi poema que incluyo como epílogo, también uso el neologismo 'brujandera' como manera de suturar los legados escindidos de la bruja y la curandera.

24 Citando los escritos de Pat Mora, Carmen Tafolla , Gina Valdés y Sandra Cisneros, Rebolledo (1995) escribe, " [.. . l la curandera [en sus escritos] no es siempre bienhechora (y es quizás por esta razón que las escritoras chicanas se sienten tan atraídas a su representación). Ella tiene la capacidad de luchar en contra de los males sociales, con la destrucción si es necesario. Ella puede buscar venganza, y a veces realmente lo hace, siendo cuidadosa de solo tomar represalias en contra de un malhechor en particular y no en general. Ella satisface nuestros deseos de buscar justicia en contra de aquellos que se perciben como más poderosos. Ella pueda ser una bruja — pero también es una curandera — . Ella puede controlar el otro mundo nebuloso, pero generalmente escoge el lado positivo, el mundo curativo. Sin embargo, cuando el mal se pone en nuestra contra, la curandera nos puede proveer de protección pública contra este mal a través de un ritual" (p. 88).

25 Encuentro curiosa esta omisión, particularmente dado que Rebolledo (1995) dice que la "[...] figura de la curandera/bruja incorpora la figura de la Virgen con aquellas deidades precolombinas con todos sus atributos" (р. 93) y cita la descripción que Anzaldúa hizo de Coatlicue como "[...] el símbolo de la libido oscura, el ctónico (el inframundo), lo femenino, el movimiento serpentino de la sexualidad, de la creatividad, la base de toda energía y la vida" (Anzaldúa, 1987 como se citó en Rebolledo, 1995, p. 93).

26 Un ejemplo reciente de las maneras en que las ideologías cristianas se manifiestan sobre la curandera-bruja 'pagana' y que persisten en la sociedad secular, es la prohibición de la novela de Rudolfo Anaya Bless Me, Ultima en un colegio de secundaria en Norwood, Colorado. Según Associated Press, "[... el el Superintendente Bob Conder dijo que algunos padres estaban ofendidos por el lenguaje obsceno y las prácticas paganas de esta novela juvenil de 1972 que trata de la vida de un niño de 7 años con su madre católica romana, Luna, y Ultima, quien usa hierbas y magia para curar [...] [Conder] dio más de dos docenas de copias de Bless Me, Ultima a un padre para ser destruidas" ("Superintendent Bans Novel from Colorado School”, 2005). 
y la sabiduría de los conocimientos curativos del curanderismo en las Américas ante perspectivas de mundo tan eurocéntricas, se reforzó consciente e inconscientemente la escisión bruja/curandera. Para descolonizar los sistemas binarios que restringen nuestro poder espiritual y sexual, me uno a Castillo (1994) en el propósito de reivindicar el "[...] término bruja para las mujeres que están conectadas con sus psiques, que permiten que sus vidas se informen de ellas y que ofrecen sus dones intuitivos a la comunidad sin temor a ser vistas como aborrecibles o locas" (p. 157). Aquellas brujas-curanderas del presente, como las mujeres que Castillo describió, las escritoras Chicanas que Rebolledo analiza y otras mujeres, trabajan para estar más conectadas consigo mismas en modos más integrales, con sus cuerpomentespiritus, como partes del mundo sagrado y natural y como fuentes de conocimiento para cambio personal y social ${ }^{27}$. Sin embargo, tal representación empoderada no es tan común como aquella de la bruja de poderes ambivalentes que al final solo inspira desconfianza y miedo.

\section{La Bruja en la cultura popular: “'Livin' la Vida Loca”}

Previamente conocido por sus baladas románticas y canciones enérgicas de pop en español, fue con “Livin' la Vida Loca” que el puertorriqueño Ricky Martin saltó a la fama del lucrativo campo del 'crossover' en $1999^{28}$. No es coincidencia que este éxito que llegó a ser número uno, represente la imagen cultural tan familiar de una latina encantadora, racializada y sexualizada, una imagen no solo exquisita, sino también apetecible para los comercializadores y consumidores de la música en ee.uu. durante el llamado 'auge Latino'29.
Los primeros versos de la canción ciertamente emplean símbolos familiares en occidente para representar el mal y el primitivismo femeninos: She's into superstitions/Black cats and voodoo dolls/ I feel a premonition/ That girl's going to make me fall, (Ella gusta de supersticiones/ gatos negros y muñecas de vúdu/ siento una premonición/ esa chica me hará caer). Reuniendo los símbolos cargados de gatos negros (asociados con brujas y mala suerte) y muñecas de vúdu (un significante general para prácticas religiosas con influencias africanas y codificadas negativamente como 'magia negra') se enlaza la historia del hacerse bruja que proviene de Europa con la del continente americano. Al igual que el ritmo pegajoso que inspira a bailar, la audiencia puede digerir y enunciar su letra fácilmente - tanto hombres como mujeres (yo también soy cómplice de esto); muchos de los que nacieron dentro de un marco cultural dominante cristiano que normaliza a la mujer como una seductora pecadora: That girl's going to make me fall, (Esa chica me hará caer). Recurriendo a más de 1.000 años de odio en contra de Eva y 500 años de discurso en contra de las brujas, estas letras reproducen la representación ambivalente de una mujer, o más bien una 'chica', sexual y espiritualmente empoderada. La 'premonición' del sujeto masculino de la canción es en realidad un testimonio de las maneras en que las mujeres son siempre culpables de hacer caer' a los hombres desde la perspectiva judeocristiana (Warner, 1983, p. 58). Según esta tradición religiosa occidental, las mujeres cargan en sí el peligroso estado salvaje de la naturaleza y la carne y, además, es “[...] obligación del cristiano, amaestrar esta naturaleza amenazante para mantener la vida del alma y la mente", misión que se cree debe ser encarnada por los hombres (Turner, 1997, p. 22).

27 Por ejemplo, véase el ensayo de Norma E. Cantú, "A Working-class Bruja's Fears and Desires" donde describe cómo con algunas amigas, apropia 'a modo de broma' una identidad bruja (2001, p. 315).

28 Es muy importante señalar que muchos latinos/as por todo el continente americano usan la frase 'la vida loca' para hacer referencia a la vida queer. Aunque no es mi enfoque en este artículo, no quiero invisibilizar esta historia cultural queer que ha experimentado su propia forma de bruijzación. En los Estados Unidos, 'la vida loca' también tiene una larga y crítica trayectoria que hace referencia a las contraculturas de jóvenes urbanos (por ejemplo, 'bato loco').

29 Apoyo el análisis de otras canciones contemporáneas que también tratan sobre una bruja sexualizada, por ejemplo, Black Magic Woman por Santana, una canción de los años 1970s que todavía es muy popular, Hechicera por el grupo de pop mexicano Maná y Tú me hiciste brujería por el grupo de salsa puertorriqueño El Gran Combo. Además, "[...] es un sistema de salud con bases firmes en la tierra y lo natural que busca balancear todos los elementos de nuestro ser" (p. 19). 
Al hacer un paralelismo entre 'esa chica' y Eva, el sujeto masculino se construye como un Adán contemporáneo. Esta lógica cultural circular de 'mujer $=\mathrm{Eva}=$ diablo $=$ mujer' justifica la actitud victimizante que reza "el diablo me hizo hacerlo". De la infidelidad a los 'crímenes pasionales', esta ideología continúa absolviendo a los hombres de asumir la responsabilidad de sus comportamientos. En esta narrativa normativa del patriarcado y culturalmente compartida, el sujeto masculino es interpelado mediante la brujería; no puede evitar vivir 'la vida loca': She'll make you take your/Clothes off and go dancing in the rain/She'll make you live her crazy life, (Ella te hará/ desnudar y bailar en la lluvia/ te hará vivir su vida loca). Además, se hace un sutil juicio de diferencia entre el sujeto masculino, que tiene una experiencia premonitoria permisible socialmente, y la mujer 'supersticiosa'- en otras palabras, ignorante e irracional一. ¿Suena familiar? ¿Quién decide cuál de los dos es el supersticioso? :Quién es siempre herético o histérico? Es más, ¿quién está interesado en mantener estas construcciones relacionales de género?

Esta distinción se despliega en las representaciones contemporáneas de las diferencias de género entre hechiceros y brujas. Mientras que la etimología de 'hechicero' como 'sabio' ha sido documentada en el diccionario Merriam-Webster, las raíces de 'bruja' como 'adivina o vidente' no han tenido lugar ${ }^{30}$. Como lo ejemplifica la popularidad de Harry Potter y sus compañeros mayoritariamente masculinos, el hechicero es legitimado como alguien dotado de magia. En cambio, la bruja sigue siendo generalmente deslegitimada como alguien supersticiosa y que practica magia demoníaca, a excepción de su uso relacionado con la atracción sexual femenina ${ }^{31}$. Castillo (1994) también señala la existencia de este doble patrón sexista entre las representaciones de las fuerzas espirituales generadas por los hombres y aquellas generadas por las mujeres en las concepciones dominantes mexicanas. Ella afirma que "[...] en la cultura mexicana, el brujo es alguien al que se teme y se venera, mientras que a la bruja se le odia hasta el punto de matarla si es posible" (p. 157) ${ }^{32}$.

La fascinación actual con las brujas en la cultura popular mediática transmite el mensaje de que las mujeres blancas que son brujas están bien- particularmente si encarnan lo que la cultura dominante considera como atractivo (es decir, piel clara, juventud y delgadez) - pero también que las brujas son otra especie completamente diferente. Haciendo parte de la historia de formación racial que asocia negativamente la piel oscura con la oscuridad moral, Martin canta Her lips are devil red/ And her skin's the color of mocha/ She will wear you out/ 'Livin' la vida loca, (sus labios de color rojo diablo/ y su piel es color moca/ te desgastará/ viviendo la vida loca). $\mathrm{Al}$ considerar las pocas representaciones mediáticas que existen de latinas en los Estados Unidos, especialmente de latinas morenas, creo que es importante reconocer que "'Livin' la Vida Loca" al menos representa una mujer de color poderosa ${ }^{33}$. A pesar de la gratificación temporal que esto produce, no podemos olvidar que su poder está contenido dentro del rubro de la brujería sexual, una construcción patriarcal muy antigua en que el poder de las mujeres se limita a modos engañosos y manipulativos. ¿Es esta canción una celebración a la mujer latina

30 La etimología de la palabra "witch" en inglés viene del anglosajón "witga", la forma más corta de "witega," que significa vidente o adivino (Walker, 1983, 1077). Tal vez "Witch" también esté relacionado con "wih" del alto alemán antiguo que significa "sagrado" (Merriam-Webster's Collegiate Dictionary, 11th ed., s.v. "witch").

31 Como lo presentan, por ejemplo, las series de televisión Sabrina, the Teenage Witch, Charmed y una serie más antigua llamada Bewitched, la cual fue estrenada como película en 2005.

32 Además, el diccionario acreditado de español, el Pequeño Larousse, expande su definición de "bruja" como una mujer que practica la "brujería" para incluir "mujer fea, vieja y de aspecto desagradable", mientras que omite las mismas o similares definiciones adicionales para "brujo". La asociación de una mujer "vieja y fea" con un aspecto malhumorado y de aspecto desagradable con la brujería, sugiere una diferenciación sexista y generacional que se enfoca principalmente en los atribuidos físicos de la mujer. El Larousse también define a la "bruja" como una "mujer de mal carácter o males intenciones" sin una definición paralela para "brujo" (El Pequeño Larousse llustrado, 2003, s.v. "bruja" y "brujo").

33 Es interesante que mientras la canción se refiere explícitamente a una mujer morena, una mujer de piel relativamente clara aparece en el video musical, lo cual sugiere la influencia reinante del ideal de belleza de la cultura occidental dominante. 
empoderada sexual y espiritualmente? ¿O es una conmiseración entre chicos sobre una lujuriosa latina 'lista para montar' que 'te desgastará' con su sexualidad voraz? Considerando que esta canción permitió a Martin entrar al rentable mercado cultural global, liderado por los EE.UU., insinúo que al final de cuentas, la canción aprueba que los chicos, blancos y morenos, celebren sus desgracias ${ }^{34}$. La referencia que la canción hace al diablo — no son solo labios de color rojo, sino color rojo diablo- sugieren aún más la asociación inherente que la mujer racializada tiene con el mal: un mal que está literalmente inscrito en su cuerpo y manifestado a través de su sexualidad. De hecho, el sujeto masculino de la canción describe un deseo ambivalente evocativo del deseo colonial que comprende la simultaneidad entre el placer y el peligro que representan las nativas, africanas y otras mujeres racializadas y sexualizadas (McClintock, 1995). La construcción cultural de la mujer latina como una bruja sexy, una 'moca' que se consume por cuenta y riesgo propio, normaliza a la latina racializada como un objeto peligroso de placer heterosexual.

Puede ser tentador para las mujeres de color usar esta forma de poder sexual, especialmente cuando históricamente ha sido o se ha percibido como la única manera de subvertir "[...] el orden socio-sexual sancionado por la religión y consagrado como sistema ético en el código de honor colonial" (Castañeda, 1998a, p. 237). Sin embargo, esta estrategia limitada ha resultado contraproducente para las mujeres. Es una táctica que no solo recodifica a las mujeres en salvajes, carnes y naturaleza dentro del marco moderno-colonial, sino también evita enfrentar un cambio estructural cultural a largo plazo. Como tal, puede que contribuya a justificar la necesidad de domesticar o 'civilizar' a las mujeres, incluso mediante la violación y otras formas de violencia. Sin embargo, es importante no culpar o avergonzar a las mujeres que encarnan su sensualidad y viven su sexualidad. Como las feministas lo han ya propuesto de manera exitosa, la violencia infligida contra las mujeres no es y nunca ha sido culpa suya (HernándezÁvila, 1993; Castañeda, 1998b). Para las mujeres, el problema no es ser una bruja sensual, una mujer empoderada espiritual y sexualmente, sino ser subordinadas por las restricciones imperantes de la cultura. Desafortunadamente, muchas de nosotras sabemos por experiencia que la bruja sexy está solo a un paso de convertirse en bruja mala y que una persona (usualmente masculina) que se sienta amenazada, enojada o dolida es con frecuencia el origen de esa redefinición. $\mathrm{O}$, dado que aprendemos a temprana edad lo que significa ser sensual mediante la mirada masculina androcéntrica y heterocéntrica, ¿Es realmente posible adoptar esta identidad para nosotras mismas? ¿Estamos siempre performando -o encarnando- lo que hemos sido socializadas a entender como sensual?

Además, como sigue la canción: Once you've had a taste of her/ You'll never be the same/ Yeah, she'll make you go insane, (Una vez que la has probado/ Jamás serás el mismo/ Sí, te hará perder la cabeza). El llegar a probarla o tener 'a taste of her' es una expresión coloquial que significa 'tener sexo con ella'. La frase popular 'I want a taste of that', (quiero una prueba de eso) viene de una familia de frases que objetiva sexualmente a las personas y a las mujeres racializadas en particular. Estas letras también resuenan con un legado de miedo en contra de las mujeres que usan sus fluidos corporales y conocimiento de las propiedades medicinales de las plantas y sus efectos para supuestamente controlar a los hombres. El miedo a la mujer sexual y espiritualmente empoderada va de la mano con el miedo por sus

34 Agradezco a Yolanda Venegas por esta reflexión. También es importante considerar que en el telón de fondo de esta colaboración "entre los chicos", hay un capitalismo global que depende de una identidad homogénea de los/las latino/as que se pueda vender y consumir mientras se le construye. A modo consciente o no, los dos autores masculinos de "Livin' la Vida Loca" y los co-productores de la mayoría de las canciones del álbum (Desmond Child y Robi Rosa) funcionan como el capitalismo tardío quiere que funcionen, traficando con la imagen femenina de la imaginación (neo)colonial para un mercado global. Tanto los hombres latinos como los euroamericanos de la industria musical y las corporaciones de los EE.UU. —dominada por los hombres — - están cosechando los beneficios. Ford Motors, por ejemplo, hizo un acuerdo con Ricky Martin para promover uno de sus carros. Como el Presidente de Ford, Jim 0’Connor, fue citado en un artículo de noticias, "El Ford Focus está dirigido al mercado juvenil y Ricky Martin está claramente cantando para ellos" ("Ford 'Livin' La Vida Loca'con Ricky Martin", 1999). 
conocimientos en 'pociones de amor'. Llamado 'hechizo sexual', estos rituales antiguos son típicamente usados por las mujeres con el propósito de 'someter' o 'domesticar' a un hombre, por ejemplo, para hacer que el hombre querido la ame, que termine su infidelidad o incluso que cese su comportamiento violento (Behar, 1989, pp. 179-80). El temor aquí es que 'tú' realmente la 'pruebes' en forma de sangre menstrual o agua para baños vaginales que ella usó previamente y posiblemente mezcló con tu comida o bebida; después de eso, mágicamente 'jamás serás el mismo', pues estarás sometido a ella.

De modo interesante, 'servir comida hechizada a los hombres' puede ser interpretado, como lo ha hecho Ruth Behar (1989) en su análisis de casos de brujería en el México colonial, como un intento de invertir el orden social y sexual que subordina a las mujeres. Es una manera literal en que la mujer puede 'penetrar' al hombre y controlar su comportamiento, frecuentemente opresivo (p. 179). Haciendo énfasis en el vínculo contemporáneo entre esta canción y aquel miedo antiguo de que las mujeres puedan invertir la jerarquía de sexo y género mediante su 'comida mágica', continuamos escuchando: she must've slipped me a sleepin' pill, (Ella tuvo que haberme dado un somnífero). Este giro contemporáneo sobre la comida hechizada en contra de un hombre que se despierta robado y desorientado, pero aún obsesionado con esta chica 'loca' que 'se robó [su] corazón', ilumina el alarmante uso de 'somníferos' (o drogas para violación), usados generalmente contra las mujeres.

Otro miedo infundado sobre la bruja es, como dice la canción, que te hará perder la cabeza o she'll make you go insane. La sociedad racista sospecha de la facultad de razonamiento de las personas de color, por lo cual nos obliga a demostrar continuamente que somos seres pensantes y que somos igual de inteligentes a las personas de la sociedad dominante. Aquí, una mujer, presuntamente irracional, pone en riesgo la salud mental de un hombre, presuntamente racional: She'll make you live her crazy life, ( Te hará vivir su vida loca). La irracionalidad que esta mujer, poderosa pero amenazante, causa, es comparada con el acto extremo e irracional del suicidio.
Aunque ella obliga al hombre a seguir su mal ejemplo (interpretaciones reminiscentes de la historia de Eva y Adán en el Libro del Génesis), hay alivio al dolor, por más ambivalente que sea: [S] he'll take away your pain/ Like a bullet to your brain, (Ella te quitará el dolor/ como una bala en tu cabeza). Como Adán, el hombre es eximido de la responsabilidad por sus propias acciones y en cambio, como Eva en la imaginación popular, esta mujer es al final de cuentas la culpable del 'loco' comportamiento del sujeto masculino.

Tales representaciones de la bruja peligrosamente poderosa son estructuradas por, y contribuyen a estructurar, el imaginario cultural que construye las mujeres como el 'otro' de los hombres (Beauvoir, 1989) y que por lo tanto justifica los intentos de restringir su poder, considerando que, en gran parte, su poder se manifiesta a través de su sexualidad y el deseo que ella puede provocar, tales representaciones promueven la creencia de que el poder de las mujeres es principal o únicamente ejercido dentro del ámbito de la sexualidad. Irónicamente, esta representación dibuja al sujeto masculino como vaciado de poder y autocontrol y se puede decir que hasta celebra esas circunstancias. No obstante, si se interpreta desde un marco cultural judeocristiano, como es común, esta misma representación absuelve al hombre de su comprensible 'debilidad' ante los actos de la mujer, la cual es construida como una seductora engañosa que se encuentra más íntimamente influenciada por la serpiente/el Diablo que el hombre (Warner, 1983). Además, como muchas feministas lo han teorizado, este enfoque de la fuerza sexual femenina sobre los hombres distrae la atención de las condiciones sociales que mantienen una balanza de poder desigual entre los sexos en general y para las mujeres de color, en particular. Mientras que la figura de la bruja desafía el binario occidental que escinde sexualidad de espiritualidad, la carne del espíritu, su poder erótico es vulnerable a ser contenido en un sistema cultural patriarcal y colonial que deslegitima su forma de espiritualidad como 'superstición' y al final la convierte en un peligro para el orden social. 
El miedo a la bruja interna y externa: "re(con)cibiendo al/lo otro"

She has this fear/Ella tiene este miedo that when she does / de que cuando reach herself/se alcance a sí misma turns around to embrace herself / se dé vuelta y se abrace a sí misma a /una

lion's or witch's or serpent's head / cabeza de león o de bruja o de serpiente will turn around / se dará la vuelta swallow her and grin / se la tragará y sonreirá.

(AnZaldúa, 1987)

\section{Al invocar a "la bestia oscura" interna y externa, que muchos nos han obligado a negar, podemos ver mejor el desmembramiento cultural y psiquico que está vinculado con las prácticas racistas y sexistas imperialistas.}

(Alarcón, 1998)

Las sociedades occidentales dominantes tienen varias razones para temerle a la Bruja y la han construido como un significante de lo otro y lo desconocido a lo que hay que tenerle miedo, y por lo tanto, debe ser controlada. Como Castillo (1994) lo ha señalado, "[...] la clave es recordar que la mujer, fértil y llena de los misterios de la reproducción, ha sido históricamente odiada y temida por los hombres solo por lo que encierra ser mujer" ( $\mathrm{p}$. 157). Ciertamente, las brujas-curanderas, en particular las parteras, han cargado históricamente con el conocimiento de la creación, procreación y sexualidad. Entre los conocimientos allí relacionados, se encuentra la dimensión erótica: 'lo erótico,' como lo ha definido ampliamente Audre Lorde, es una energía transformativa que extiende puentes entre lo espiritual y lo sexual/sensual y facilita un sentido de compleción y conexión con el propio ser al igual que con los otros en todas sus diferencias y similitudes. Lorde (1984a) señala que las culturas occidentales han construido un miedo hacia lo erótico. Han despojado a lo erótico de su asociación con eros como amor y 'energía creativa' (p. 55), y en cambio se han enfocado en su conexión con la pornografía, que según Lorde, “[...] se enfatiza en la sensación sexual sin sentir" (p. 54). Este miedo se relaciona con la aprehensión de involucrarse emocional y espiritualmente. Es el miedo de sentir más allá de los sentimientos superficiales. Nuestra sociedad supuestamente acepta las 'sensaciones nuevas,' como celebra “'Livin' la Vida Loca”, pero estas con frecuencia son sensaciones que principalmente están desprovistas de contenido, o como lo articularía Lorde, que carecen de 'sentimientos profundos' (p. 58). Además, ella afirma:

[...] como mujeres, hemos aprendido a desconfiar del poder que surge de nuestro conocimiento más profundo y no-racional. Todas nuestras vidas hemos sido alertadas en su contra por el mundo masculino, que valora esta profundidad del sentir lo suficientemente como para mantener a las mujeres alrededor y en ejercicio de ésta al servicio de los hombres, pero que teme demasiado de esta profundidad para examinar sus posibilidades en sí mismos. (Lorde, p. 54).

Es la experiencia empoderadora de este sentimiento profundo, o del erotismo, que crea un bienestar y conexión al interior de sí mismo y en relación con otras personas y la tierra en conjunto. Entre más a menudo estén las personas en este estado, es menos probable que subordinen a otras o permitan que otros las dominen. Como bien lo ha señalado Anzaldúa (2002a) en su teoría del conocimiento:

Con admiración y asombro ves alrededor, reconociendo el valor de la tierra, la santidad de cada ser humano en el planeta y la unidad e interdependencia última de todos los seres - somos todos un pais. El amor surge en tu pecho y es lanzado desde el chakra del corazón, enlazándote con todos/todo [...] Compartes una categoría de identidad más amplia que cualquier posición social o etiqueta racial. Este conocimiento te motiva a trabajar activamente para asegurarte de que ningún daño se haga a la gente, a los animales, al océano- a asumir el activismo espiritual y el trabajo de sanación. (p. 558).

Como lo explora Anzaldúa (2000) en su obra, este trabajo de consciencia puede resultar en la reconexión con la energía erótica al interior y al exterior de cada uno y "[...] conecta la vida interna de la mente y el espíritu con los mundos externos de la 
acción” (p. 178), lo que ella reconoce como "activismo espiritual".

Las Brujas también inspiran miedo porque tienen la habilidad de 'volar' y porque harán ejercer sus epistemologías espirituales, o lo que Anzaldúa (1987) llama la facultad (pp. 38-39), sin importar los intentos psicológicos y físicos de controlarlas ${ }^{35}$. Como metáfora de la libertad, volar sugiere un cuerpomentespiritu descolonizado (Lara, 2002). Las brujas rechazan creer las mentiras sobre su maldad inherente y sobre la maldad del mundo natural, pues las sofocan y disminuyen. Ellas saben que a pesar de los mensajes misóginos que sugieren lo contrario, la mujer, como la madre tierra, es buena, o más bien, es compleja y se extiende más allá de las categorías disyuntivas de lo bueno y lo malo. Además, como nos lo recuerda Aurora Levins Morales (1998) las brujas son videntes que no temen ver y decir lo que ven cuando vuelan:

Una de las acusaciones más comunes contra las brujas son sus vuelos nocturnos: la habilidad de cambiar de forma o dotar de poderes mágicos a los objetos domésticos, como una olla o una escoba, y elevarse por el paisaje cotidiano con ojos que pueden penetrar la oscuridad y ver lo que se supone no debemos ver... aquellas que pueden ver en la oscuridad pueden descubrir secretos: ires y venires ocultos, transacciones y escapadas, el movimiento clandestino de unas tropas, capas de la vida que se conducen normalmente fuera de la vista. (p. 49).

La voluntad de volar, "[...] dejar el familiar suelo y ver lo que significa estar escondido” (p. 49), puede ser una de las cualidades más socialmente amenazantes de la Bruja. Al esforzarnos para ver desde una perspectiva holística y vincular los mundos espirituales y físicos, la Bruja nos sirve como ejemplo para tal visión holística. Como Morales lo ha sugerido, una política del holismo incluye el discernir las maquinaciones opresivas del poder que "[...] se conducen normalmente fuera de vista" y que afectan a los subyugados negativamente (p. 49).

Con esta facultad cultivada que la ayuda a leer los signos del poder para responderles o resistirles más eficazmente, la Bruja es un símbolo apropiado para una 'metodología de los oprimidos'. Chela Sandoval (2000) teoriza esta metodología como un "[...] conjunto de procesos, procedimientos y tecnologías para descolonizar la imaginación” (p. 68). De hecho, Sandoval cita la descripción que hace Anzaldúa sobre una figura que parece una bruja, "La naguala", en un epígrafe: "Ella está dispuesta a $[\ldots]$ hacerse vulnerable a los modos extranjeros de ver y pensar. Ella entrega toda noción de seguridad, de lo familiar. Deconstruir, construir. Ella se hace una nabual, capaz de transformarse en un árbol, un coyote, otra persona" (Anzaldúa, 1987 citado en Sandoval, 2000, p. 66). Como una 'naguala' chamanística o una 'perceptora de cambios' que cambia formas (Anzaldúa, 2002, p. 542) ${ }^{36}$, la Bruja puede transformarse en lo que necesita para hacer su trabajo de transformaciones sociales. Consciente de su interrelación con los otros y con el universo, la Bruja se transforma a sí misma y al mundo exterior, sabiendo que ella forma parte integral de éste, a través de sus palabras, imágenes, activismo u otro 'trabajo curandero' (Pérez, 1998,

35 En la discusión sobre cómo Anzaldúa en Borderlands/La Frontera (1987) “[... devuelve al centro de nuestra perspectiva, la importancia por los modos de saber a través de nuestros espíritus y que han sido marginalizados", Laura E. Pérez (1998) da el ejemplo de cómo "'La facultad" y otras formas de 'conocimiento interior' afirman lo 'divino interior' (p. 50), así como lo 'sobrenatural' (p. 49) o 'el mundo de los espíritus' (p. 38), y representa formas alternativas de percepción ('videncias', pp. 39, 42, 45) y 'otros modos de consciencia' (p. 37), y por lo tanto, otras epistemologías y rutas de conocimiento (pp. 37, 42) fuera de la racional como se ha entendido y privilegiado en las culturas euroamericanas y europeas dominantes" (р. 52).

36 Anzaldúa (2002) desarrolla: "Naguala es la forma femenina de nagual, la capacidad que algunas personas tienen, como los chamanes indígenas de México, para 'cambiar formas'- hacerse un animal, un lugar o una cosa 0 cambiarse a la perspectiva de su compañero animal. He extendido el término para incluir un aspecto del propio ser desconocido que se hace consciente. Nagualismo es un conocimiento espiritual mexicano en el que el practicante busca señales de los espíritus. Llamo a la creadora de las señales de los espíritus 'la naguala', una consciencia creativa y onírica que puede hacer asociaciones y conexiones más amplias que aquellas de la consciencia despierta" (p. 577). 
p. 41) $)^{37}$. Tal habilidad de transformarse a sí misma, al igual que las situaciones que son potencialmente plagadas de injusticia, también son temidas como una amenaza para el poder dominante.

Dado el violento legado de la brujización, conectado a la violencia discursiva y física contra "[...] la mujer indígena, difamada y abusada" (Alarcón, 1998, p. 375; Anzaldúa, 1987, pp. 22-23, pp. 42-43), y las maneras en que los humanos internalizamos miedos ante el 'otro', se puede entender que muchas de nosotras hayamos internalizado un miedo hacia la Bruja, tanto en aspectos de nosotras mismas como en los demás. De hecho, puede que las instituciones coloniales y patriarcales sean culpables de la hechicería más grande de todas, al fomentar mediante sus tecnologías de poder esta internalización que nos previene de re-membrar ${ }^{38}$, desarrollar y construir la parte curandera-bruja en nuestro interior y de valorarla entre nosotras. Además, como lo ha escrito Inés Hernández-Ávila (2002) con tanta fuerza, las violencias del colonialismo han creado muchas heridas en el espíritu, incluyendo, y ahí yo propondría, este proceso de brujización. Ella señala que a pesar de que "[...] nos hemos ido recuperando desde el momento en que empezamos a cuestionar, conocer y entender", muchas de nosotras hemos internalizado "la peor clase de hechicería", la creencia de que "[...] jamás nos recuperaremos de la violencia o de que únicamente nos recuperaremos lentamente y con mucho dolor" (p. 534). La brujacurandera como 'activista espiritual' está en el proceso de encarnar y vivir este conocimiento espiritual, re-membrando y creando saberes poderosos para la sanación personal y comunitaria.
Curarse de dichos desconocimientos coloniales comprende un esfuerzo exigente. Como lo explora Anzaldúa, el proceso de re-membrar y construirse las múltiples y dinámicas identidades está cargado de miedos. En particular, ella aborda el miedo de ser 'tragado' por el propio lado 'oscuro' u 'oscurecido', lo que ella ha descrito varias veces como "[...] la cabeza de un león o una bruja o una serpiente" (1987, p. 43) y que en sus términos la ha llamado 'Shadow Beast' (Sombra bestia) (pp. 20, 44) y musa bruja (p. $72)^{39}$. En el contexto de la filosofía de la dualidad nahua de la que bebe Anzaldúa, ser 'tragado' por la Bruja no significa ser destruido, al menos no en su sentido último. Es más un acto de recibir y reconcebir el propio ser en su compleción, de hecho, en "re(con)cebir ${ }^{40} \mathrm{al} /$ lo otro" (Keating, 1996 como se citó en Anzaldúa, 2002, p. 570). Es una integración de supuestos contrarios y un abrazo que conjuga integralmente al ser, a pesar de los intentos colonizadores de mantener las propias 'oscuridades' y 'claridades' de forma escindida y por lo tanto con menos fuerza. De hecho, Anzaldúa (1987) reconceptualiza 'la oscuridad' y 'la luz'. Ella escribe:

Soy un amasamiento, soy un acto de amasar, de unificar y juntar que no solo ha producido tanto una criatura de la oscuridad y una criatura de la claridad, sino también una criatura que cuestiona las definiciones de lo claro y de lo oscuro y les da nuevos sentidos. (p. 81).

Al teorizar desde sus experiencias propias y sus estudios de las ideas y la psicología arquetípica nahua, Anzaldúa explora el papel de lo que ha llamado 'Estado Coatlicue' en la formación del sujeto. Este proceso " $[. .$.$] antecede un cruce espiritual y político$

37 Véase el ensayo de Laura E. Pérez (1998), "Spirit Glyphs: Reimagining Art and Artist in the Work of Chicana Tlamatinime" que ha sido muy formativo para mi pensamiento. Allí describe el trabajo de varias escritoras y artistas chicanas que se comprometen en el "trabajo curandero: reclamar y reformular las visiones espirituales del mundo que las empoderan como mujeres y que, en el mismo gesto, re-imaginan lo que significa el rol social de arte y el artista" (p. 41).

38 Lara usa "re-membering" para representar dos sentidos simultáneos: a) traer a la memoria y b) la idea de membering comprende a los miembros del cuerpo que se reconstituyen, dejan de estar fragmentados y retornan a un solo cuerpo (re-membering es entonces el contrario de dismembering 0 desmembrar) (N. de T.).

39 Véase el análisis de Erika Aigner-Varoz (2000) sobre la "Sombra-bestia serpentina" de Anzaldúa como "[... ] una reapropiación, una reinscripción y sobre todo, una síntesis de las viejas metáforas que etiquetan o excluyen las mujeres, los de piel oscura y los homosexuales en maneras negativas" (p. 60).

40 Lara juega con dos términos en esta palabra: receive (recibir) y reconceive (reconcebir) y lo hace explícito con la preposición (con) en el medio; este juego no fue posible mantenerlo en el verbo infinitivo en español, aunque sí funciona en el gerundio 're(con)cibiendo'. Para mantener el dinamismo de su propuesta, planteó el juego entre los artículos que reciben la acción y duplican su sentido sobre el objeto (N. de T.).

Polisemia No. 22, 33 - 53. Posicionalidades brujas: hacia un activismo de espiritualidad chicana/latina. Bogotá, ISSN: 1900-4648. Julio - diciembre de 2016 
a través del cual uno llega a una consciencia espiritual y política más alta"(Saldívar-Hull, 1999, p. 7). Ella comienza con el miedo de no conocerse a sí misma y de perderse o quedarse atrapada en la 'oscuridad' de la psique o el 'submundo' espiritual; Anzaldúa (1987) siente temor de "[...] no encontrar las muescas que hizo en los árboles y que no encontrará la forma de volver" (p. 43). Pero después de pasar por el torbellino del Estado Coatlicue y abrazar a su 'Bestia,' Anzaldúa logra manifestar: 'no tengo miedo' (p. 51). Sin embargo, dado que este es un proceso continuo, - pues no solo nos enfrentamos continuamente a discursos y estructuras de poder que cuestionan nuestras existencias, sino que nosotros mismos somos siempre sujetos-en-proceso de que el miedo latente pueda también volver- ${ }^{41}$. Es particularmente alentador invocar las palabras de Lorde en este contexto: "Cuando me atrevo a estar en poder para usar mi fuerza al servicio de mi visión, se hace cada vez menos y menos importante el hecho de tener miedo" ${ }^{\prime 2}$. En este caso, nuestra 'visión' liberatoria nos llama a 'cuestionar, conocer, y entender' (Hernández-Ávila, 2002, p. 534) - y, ciertamente a curar- lo que Alarcón (1998) describe como "[...] el desmembramiento cultural y psíquico que está vinculado a las prácticas racistas y sexistas imperialistas" (p. 375). Poner en práctica tal sanación significa crear una visión decolonial del amor: el amor propio, el amor al otro como "una hermenéutica de cambio social” (Sandoval, 2000).

\section{Posicionalidades brujas: “...solo con nuestra magia"}

Si las prácticas críticas de las feministas chicanas han sido, como lo ha llamado Laura E Pérez, 'desestabilizantes' del nacionalismo chicano, así como del estado-nación de los EE.UU. (1999), entonces las brujas - que han estado causando problemas a las sociedades dominantes por siglos - son un símbolo apropiado que el feminismo Chicana/Latina ${ }^{43}$ puede recuperar. Si nuestro trabajo busca ser transformador a nivel personal y social, ¿qué mejor símbolo que la bruja, cuyo trabajo y palabras tratan sobre la transformación? Para algunas de ustedes que no se sienten cómodas con hacer de la 'bruja' una de sus identidades, la Bruja puede funcionar como una posicionalidad crítica. Como los estudios culturales chicanas lo han articulado ya desde hace un tiempo, existen una "[...] multiplicidad de posiciones de sujetos [...] con raíces en nuestras comunidades" (Fregoso \& Chabram, 1990, pp. 208-209). Mi propuesta es que elaboremos más en las maneras en que las brujas puedan constituir una de ellas. ¿Qué se hace posible cuando hablamos y escuchamos desde y a través de nuestras posiciones brujas? ¿Qué pudiéramos imaginar, pensar y sentir que no pudiéramos hacer de otro modo? ¿Cómo seríamos más capaces de construir solidaridad con esas 'otras' oscuras, indias, putas, queers, marginadas y difamadas?

Algunos dirán que nosotras investigadoras, activistas y artistas chicanas y latinas no estamos listas para salir del armario espiritual, mucho menos identificarnos como brujas simbólicas o literales, por lo menos no en público ${ }^{44}$. Esta inquietud está bien justificada. Aunque nos esforzamos por transformarnos a nosotras mismas y a nuestros mundos, la realidad es que formamos parte de una sociedad que todavía está ampliamente organizada alrededor de modos de conocer binarios que son racistas y sexistas. Mientras nos forjamos espacios transformadores en una profesión que está construida sobre

41 Tomo inspiración de las lecturas profundas de Erika Aigner-Varoz (2000), Sonia Saldívar-Hull (1999), Caridad Souza (n.d.) y Norma Alarcón'(1998) de "Shadow-Beast" y el "Coatlicue State".

42 Esta cita se le atribuye a Lorde en una tarjeta postal y en varias páginas biográficas (por ejemplo, http://www.femmenoir.net/Leaders-Legends/ AudreLorde.htm). No logré encontrar su fuente original en publicación.

43 Después de la lucha revindicativa del movimiento chicano en la era de los derechos civiles en EE.UU., aparece en la academia el campo de los Chicano Studies. Como respuesta, las feministas chicanas evidencian la necesidad de usar términos incluyentes de la experiencia femenina dentro de este campo y actualmente se le conoce como Chicano, Chicana Studies. Dentro de esta apuesta feminista, Chicana se ha ido conjugando con Latina como forma de ir incluyendo las distintas experiencias históricas de ser Brown en Estados Unidos; la primera es una experiencia que habla de varias generaciones en ese territorio (pre y post la nueva línea fronteriza entre los dos países por el Tratado Gudalupe-Hidalgo) y la segunda refiere a las nuevas generaciones de migrantes. (N. de. T).

44 También es importante considerar que, para mucha gente en un contexto cultural indígena, no es apropiado llamarse curandera, sanadora 0 bruja en lo que a esto respecta, porque tales títulos deben ser dados por las comunidades a las que se sirve. Dichos títulos de honor son dados en reconocimiento de los muchos años de aprendizaje y las habilidades o dones que tiene, por lo que conllevan una gran responsabilidad social. 
bases rígidas de la razón que se invalida y binariza a sí misma con respeto a los saberes espirituales e intuitivos (Hooks, 1994), seguimos siendo juzgadas por ese mismo sistema de valor. Además, considerando el prejuicio cultural que considera a las brujas como malas, nos arriesgamos a estar asociadas con lo maligno y todos los otros atributos oscuros que forman lo malo en el binario del bien y mal y con el que ya estamos asociadas por nuestro género y raza (es decir, femeninas, naturales, carnosas, terrosas, emocionales, irracionales y lujuriosas). Y definitivamente no necesitamos más combustible que pueda ser usado como excusa para suprimir a las mujeres de color. Puedo imaginar los pensamientos silentes pero potentes: 'que no le den el cargo, ella es una bruja,' o 'ella obtuvo el cargo, porque es una bruja'.

Entre más públicas seamos con nuestra brujandería ${ }^{45}$, nos arriesgamos también a estar más expuestas al criticismo nocivo, o en términos espirituales, a la energía que no es de nosotros, incluyendo la envidia. No es necesariamente 'mala' energía, pero es definitivamente energía que no nos pertenece y que puede afectar las concepciones de nosotras mismas, fomentando potencialmente a que baje la autoestima y que nos lleve a cuestionarnos si nuestro trabajo es verdaderamente necesario y beneficioso o que nos impida a realizar nuestro trabajo transformador. Dado el legado documentado e indocumentado de una política de violencia en contra de las brujas, la preocupación es real.

Además, como lo expresó Castillo, es importante ser prudente cuando nos referimos a nosotras mismas o a otra persona como bruja, porque en 'el mundo de la brujería real', hay gente que está dispuesta a llevarse el poder de la bruja para sí mismo y hasta puede matar por él. Como ella lo sugiere, una cosa es referirse a uno mismo como bruja en broma, en un espacio 'seguro-por ejemplo, ella se refiere a un grupo de latinas que se reúnen cada año en oración y rejuvenecimiento espiritual como las bellas brujas - y otra cosa muy distinta es 'anunciarlo. Castillo afirma, "No me gusta que se use esa palabra en modos ligeros. En México es una palabra muy, muy poderosa y por buenas razones", eso tiene que ser respetado ${ }^{46}$.

Todas estas inquietudes son importantes. Sin embargo, continúa la necesidad de "transformar silencio en lenguaje y acción” (Lorde, 1984b). Como investigadoras comprometidas con la justicia social, es nuestra responsabilidad auto-definirnos y redefinir, hablar y actuar, a pesar de los miedos que las amenazas reales nos provoquen. Como Lorde nos ayuda a recordar, hablemos y actuemos o no lo hagamos, el miedo puede seguir estando ahí. No podemos darnos el lujo de vivir sin miedo y en condiciones de completa 'seguridad'. Debemos hablar y actuar a pesar del miedo, a través del miedo y fortalecidas por el propósito de nuestra visión. Aunque hablar nuestra(s) verdad(es) es un reto y un logro a ser reconocido, esto no es suficiente. Al plantear la inquietante pregunta " ¿Puede hablar el subalterno?”, Gayatri Spivak (1988) nos recuerda que no basta con hablar, sino que también debemos ser escuchados. Para este fin, debemos trabajar para transformar las ideologías y estructuras sociales que mantienen los desconocimientos antiguos y que no escuchan nuestras voces.

Además, en su hechizante misiva Speaking in Tongues: A Letter to Third World Women Writers (1983), Anzaldúa eleva nuestra consciencia sobre aquellos que "[...] tienen palabras y lengua [pero] no tienen orejas, [aquellos que] no pueden escuchar y no oirán" (p. 173). Ella nos recuerda que para actuar los cambios libertarios, uno debe desarrollar una práctica crítica de escucharse a sí mismo y a los demás. Esta también es la lección de la Bruja: necesitamos escuchar nuestros corazones, intuiciones, subconscientes, cuerpos, cuerpomentespiritus, lo que sea que queramos que nuestras facultades de conocimiento incluyan y como queramos llamarlas, pero que van más allá de nuestras mentes racionales. Como activistas espirituales debemos nutrir nuestra habilidad de escucharnos a través de las diferencias. Contestarnos los unos a los

45 Véase nota 23.

46 Entrevista personal, 12 de Diciembre 2002a. También véase Castillo (2002b). 
otros no nos llevará muy lejos, si no escuchamos de vuelta. Claro, hay algunos que pueden negarse a escucharnos y negarse a reconocer nuestra humanidad completa. Como Anzaldúa lo ha explorado en Speaking in Tongues, están aquellos que - por miedo de nuestro poder para hablar, crear, transformar, amar y promulgar otras formas de magia, en modos revolucionarios - tratarán de callarnos y excluirnos. Sin embargo, los miedos de los demás no pueden prevenirnos de trabajar hacia nuestra compleción, como individuos y como una comunidad del mundo. Acoger una posicionalidad bruja significa abrazar nuestra existencia completa y las existencias completas de otras mujeres de color, de hecho, de todos los 'otros' que han sido otrerizados y fragmentados en maneras similares. Ciertamente, cuando escucho a mi ser, sé que todos estamos conectados. Con Anzaldúa y otras brujanderas, ruego por que usemos todos nuestros poderes-incluso nuestros poderes eróticos-para trabajar en la compleción y conexión de nuestros seres, entre nosotros mismos, la tierra y el cosmos porque es por estos actos de conexión que la transformación es posible.

\section{Epílogo: encarnando una posicionalidad bruja}

Hay infinitas maneras de asumir una posicionalidad bruja. Hace parte de una de las múltiples posiciones de sujeto de la que podemos entrar y salir y no es para encarnar todo el tiempo. Vuelvo a la historia con la que inicié este ensayo, para compartir con ustedes algunas de las maneras en que he vivido esta posicionalidad. Como lo sugirió la reacción de este joven con la que empecé, el miedo a ser hechizado o de sentirse controlado puede generar acusaciones de 'bruja mala'. De hecho, mientras no contestes y sigas los deseos de los demás, en este caso una mujer siguiendo los del hombre, puedes mantenerte en gracia y hasta ser celebrada por tu poder 'femenino'. Como hemos visto, y quizás lo han experimentado por ustedes mismas como yo, hay una delgada línea entre una bruja mala y una bruja buena, una línea a menudo ambigua que ha sido definida por los agentes del patriarcado. De hecho, los discursos dominantes, repletos de binarios, nos harían creer que las brujas 'malas' y las 'buenas' no viven realmente en las fronteras ni en los mismos espacios intersticiales y ni siquiera en los mismos cuerpos.

Aunque tuve miedo, al principio, de las palabras misóginas que me llevaron a cuestionar mi comportamiento, e incluso mi ser, las dejé ir. Y en vez de internalizar la acusación que carga el peso milenario de culturas patriarcales, escribí un poema para validar mis instintos y mi poder erótico, al igual que para honrar la orisha (ser divino) Ochún, a quien invoqué con respeto antes de salir a bailar con mis amigas esa noche. En las creencias y practicas Yoruba que llegaron al continente americano con la esclavitud y que ahora se practican como Santería, Lucumí, y otras prácticas curativas y espirituales - frecuentemente brujizados y malinterpretados-, Ochún es la orisha de agua dulce que en la concepción popular, representa la energía del amor y lo erótico, y “[...] es dueña de los genitales femeninos y del huevo femenino" (Castellanos, 2001, p. 42 ${ }^{47}$. Con la esperanza de extender mis conocimientos más allá de mí misma e inspirar una consciencia y un diálogo transformativo, hice la lectura de 'Brujandera' en un encuentro de poesía latina/o en San José, California, en 1999 durante la lunada, en luna llena, por supuesto.

\section{Brujandera ${ }^{48}$}

Me pongo la pulsera de cuentas amarillas/
I slide on the yellow-beaded bracelet
acaricio mis caderas fuertes, fértiles /
caress my strong hips and fertility thighs
peino mis rizos negros / comb my curly locks

47 Para introducirse más a fondo en la práctica y filosofía de la Santería, véase "Altar of my Soul: The Living Tradition of Santería" de la académica y también iniciada a la Santería, Marta Moreno Vega. 
limpio mi alma con salvia /

cleanse my soul with sage

Contemplo mi ser / I behold my being

$\mathrm{y}$ me embrujo / and am bewitched

Te invoco querida Ochún /

I invoke you beloved Ochün

en busca de la llama de mi pasión /

in search of the flame of my passion

no necesariamente a mi Changó ${ }^{49}$ allá /

not necessarily my Changó out there

sino, al Changó de aquí /

but rather my Changó in here

en los labios de mi corazón /

on the lips of my lit heart

y en el corazón de mi panocha /

and in the heart of my 'panocha'

busco la fuente de mi deseo /

I seek the river of my desires

y en mi lengua / and on my tongue of fire también la encontraré / I will also find it

Mi lengua / my tongue
capaz de seducir / likely to seduce
con sus palabritas suavecitas /
with her slow smooth words
sabor de miel / honey flavored

Lengua hambrienta / my hungry tongue capaz de seducirme / likely to seduce me con su saliva sabor de ron / with her salty saliva and taste of rum

Lengua que se suelta / my flying tongue hacia mi liberación /

that lets loose for 'liberación'

Yo soy una mujer sincera /

I am a sincere woman

que goza del amor / who enjoys love, loving

Puta, no / whore, no

pura, tampoco / nor virgin

ipura puta bruja sí! /

pure whore virgin bruja yes!

consciente / conscious

vestida en toda "nuestra América" /

dressed in all of "our América"

Ochún, curandera panochera /

Ochún, curandera panochera

me entrego a tu poder / I trust in your power

bailo en el fuego de tus aguas /

I dance in the fire of your waters

$\mathrm{y}$ en tu dulce calor / and in your sweet heat

seguiré / I will remain

¿Bailamos? / Dance, anyone?

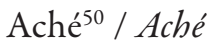

48 El poema Brujandera fue escrito originalmente en español. El texto en inglés es una traducción que ella incluye para su publicación en la revista Chicana/Latina Studies. (N. de T.).

49 Changó es el elemento natural y honrado del "relámpago, trueno y fuerza" y representa la majestuosa ferocidad y el espíritu guerrero (Murphy, 1993, p. 182). Como lo ha desarrollado más a fondo Isabel Castellanos (2001), también "[...] reina sobre los órganos sexuales de los hombres y del semen que impregna a las mujeres" (p. 42) y es uno de los amantes de 0chún (p. 35). Además, "personifica -junto con Ochún- la alegría de vivir" (p. 41).

50 En Santería, "aché" significa "poder, gracia, crecimiento, sangre". Es "la fuerza vital de Dios, los orishas y la naturaleza" (Murphy, 1993, p. 175). 


\section{Referencias}

Aigner-Varoz, E. (2000). Metaphors of a Mestiza Consciousness: Anzaldúa's Borderlands/La Frontera. Melus, 25 (2), 47-63.

Alarcón, N. (1998). Chicana Feminism: In the Tracks of 'the' Native Woman. En C. Trujillo (ed.), Living Chicana Theory. Berkeley: Third Woman Press.

Alarcón, N. (1989). Traddutora, Traditora: A Paradigmatic Figure of Chicana Feminism. Cultural. Critique, (13), 57-87.

Anzaldúa, G. (2002). Now let us shift the path of conocimiento inner work, public acts. En G. Anzaldúa y A. Keating (eds.), This bridge we call home: radical visions for transformation. New York: Routledge Press.

Anzaldúa, G. (2000). Interviews/Entrevistas: Gloria E. Anzaldúa. New York: Routledge Press.

Anzaldúa, G. (1987). Borderlands/La Frontera: The New Mestiza. San Francisco: aunt lute books.

Anzaldúa, G. (1983). Speaking in Tongues: A Letter to Third World Women Writers. En C. Moraga y G. Anzaldúa (eds.), This Bridge Called My Back: Writings by Radical Women of Color. Latham, N. Y: Kitchen Table/ Women of Color Press.

Avila, E., y Parker, J. (1999). Woman Who Glows in the Dark: A Curandera Reveals Traditional Aztec Secrets of Physical and Spiritual Health. New York: J. P. Tarcher/Putnam.

Barstow, A. L. (1994). Witchcraze: A New History of the European Witch Hunts. San Francisco: Pandora.

Beauvoir, S. (1989). The Second Sex. En H. M. Parshley (trad.). New York: Vintage Books.

Behar, R. (1989). Sexual Witchcraft, Colonialism, and Women's Powers: Views from the Mexican Inquisition. En A. Lavrin (ed.), Sexuality and Marriage in Colonial Latin America. Lincoln: University of Nebraska Press.

Behar, R. (1987). Visions of a Guachichil Witch in 1599: A Window on the Subjugation of Mexico's Hunter Gatherers. Ethnohistory, 3(2), 115-38.
Blötzer, J. (2003). Inquisition. The Catholic Encyclopedia (Vol. VIII). Recuperado de http://www.newadvent.org/cathen/08026a. htm

Cantú, N. (2001). A Working-class Bruja’s Fears and Desires. En Latina Feminist Group (ed.), Telling to Live:Latina Feminist Testimonios. Durham. N.C.: Duke University Press.

Castañeda, A. (1998a). Engendering the History of Alta California, 1769-1848. En R. Gutierrez y R. Orsi (eds.), Contested Eden: California Before the Gold Rush. Berkeley: University of California Press.

. (1998b). History and the Politics of Violence Against Women. En C. Trujillo (ed.), Living Chicana Theory (pp.310-19). Berkeley: Third Woman Press.

. (1998c). Witchcraft on the SpanishMexican Borderlands. En W. Mankiller, G. Mink, M. Navarro, B. Smith, y G. Steinem (eds.), The Reader's Companion to U.S. Women's History (pp. 638-39). Boston: Houghton Mifflin Company.

Castellanos, I. (2001). A River of Many Turns: The Polysema of Ochün in Afro-Cuban.

Tradition. En Murphy y M. Sanford (eds.), Osún Across the Waters: A Yoruba Goddess in Africa and the Americas (pp. 34-45). Bloomington: Indiana University Press.

Castillo, A. (2002a). Entrevista hecha por la autora, grabada en Austin, Tex., 12 diciembre. . (2002b). An Enlightened Church? Letters to Young Catholics. Culturally Catholic. Conscience, XXIII (2), 7-8.

(1994). Massacre of the Dreamers: Essays on Xicanisma. Albuquerque: University of New Mexico Press.

Dávalos, K., \& Partnoy, A. (2004). Editors' Commentary: Translating the Backslash. Chicana/Latina Studies: The Journal of Mujeres Activas en Letras y Cambio Social, 4 (1), 6-18.

Ehrenreich, B., \& Deidre, E. (1973). Witches, Midwives, and Nurses: A History of Women Healers. New York: The Feminist Press at City University of New York. 
Fregoso, R., \& Chabram, A. (1990). Chicana/o Cultural Representations: Reframing Alternative Critical Discourses. Cultural Studies, 4 (3), 203-12.

"Ford 'Livin' La Vida Loca' With Ricky Martin." (1999). Recuperado de http://launch.yahoo. $\mathrm{com} / \mathrm{read} /$ news/12051796, 9 septiembre.

Giles, M. (1999). Introduction to Women in the Inquisition: Spain and the New World. Baltimore: Johns Hopkins University Press.

Glass-Coffin, B. (1998). Madre, Mujer, Bruja. En The Gift of Life: Female Spirituality and Healing in Northern Peru (pp. 35-46). Albuquerque: University of New Mexico Press.

Greenleaf, R. (1969). The First Decade of the Mexican Inquisition: 1522-1532. En The Mexican Inquisition of the Sixteenth Century (pp. 7-44). Albuquerque: University of New Mexico Press.

Hernández-Ávila, I. (2002). In the Presence of Spirit(s): A Meditation on the Politics of Solidarity and Transformation. En G. Anzaldúa y A. Keating (eds.), This bridge we call home: radical visions for transformation (pp. 530-538). New York: Routledge Press. . (1993). In Praise of Insubordination, or What Makes a Good Woman Go Bad? En E. Buchwald, P. Fletcher y M. Roth (eds.), Transforming a Rape Culture (pp. 375-92). Minneapolis: Milkweed Editions.

Hooks, B. (1994). Teaching to Transgress: Education as the Practice of Freedom. New York: Routledge Press.

Keating, A. (2005). Shifting Perspectives: Spiritual Activism, Social Transformation, and the Politics of Spirit. En E. Anzaldúa y A. Keating (eds.), EntreMundos/AmongWorlds: New Perspectives on (pp. 241-254). New York: Palgrave/Macmillan. (2002). Forging El Mundo Zurdo: Changing Ourselves, Changing the World. En G. Anzaldúa y A. Keating (eds.), This bridge we call home: radical visions for transformation (pp. 519-30). New York: Routledge Press. . (1996). Women Reading Women Writing: Self-Invention In P. G. Allen, G. Anzaldúa \& A. Lorde. Philadelphia: Temple University Press.
Klor de Alva, J. (1991). Colonizing Souls: The Failure of the Indian Inquisition and the Rise of Penitential Discipline. En M. Perry y A. Cruz (eds.), Cultural Encounters: The Impact of the Inquisition inSpain and the New World (pp.3-22). Berkeley: University of California Press.

Lara, I. (2002). Healing Sueños for Academia. En G. Anzaldúa y A. Keating (eds.), This bridge we call home: radical visions for transformation (pp. 433-38). New York: Routledge Press.

Lavrin, A. (1989). Introduction: The Scenario, the Actors, and the Issues. En A. Lavrin (ed.), Sexuality and Marriage in Colonial Latin America (pp. 1-43). Lincoln: University of Nebraska Press.

Lorde, A. (1984a.). Uses of the Erotic: The Erotic as Power. En Sister Outsider: Essays and Speeches (pp. 53-59). Trumansburg, N.Y.: The Crossing Press.

(1984b). The Transformation of Silence into Language and Action. En Sister Outsider: Essays and Speeches (pp. 40-44). Trumansburg, N.Y.: The Crossing Press.

Martin, R. (1999). “Livin' La Vida Loca.” En Ricky Martin [CD]. Estados Unidos: Sony Music Entertainment Inc.

McClintock, A. (1995). The Lay of the Land: Genealogies of Imperialism. En Imperial Leather: Race, Gender, and Sexuality in the Colonial Contest (pp. 21-74). New York: Routledge Press.

Morales, A. (1998). Nightflying: Transforming Traumatic Memory. En Medicine Stories: History, Culture, and the Politics of Integrit (pp. 45-49). Cambridge, Mass.: South End Press.

Murphy, J. M. (1993). Santeria: African Spirits in America. Boston: Beacon Press.

Nelson, M. (1975). Why Witches Were Women. En Jo Freeman (ed.), Women: A Feminist Perspective (pp. 335-50). Palo Alto, Calif.: Mayfield Publishing Co.

Quezada, N. (1991).The Inquisition's Repression of Curanderos. En M. E Perry y A. J. Cruz (eds.), Cultural Encounters: The Impact of the Inquisition in Spain and the New World (pp. 3757). Berkeley: University of California Press. 
(1975). Amor y magia amorosa entre los Aztecas: supervivencia en el México colonial. México, D.F.: Universidad Autónoma de México.

Pérez, L. (1999). El desorden, Nationalism, and Chicana/o Aesthetics. En Alarcón, C. Kaplan, y M. Moallem (eds.), Between Woman and Nation: Nationalisms, Transnational Feminism, and the State (pp. 19-46). Durham, N.C.: Duke University Press.

. (1998). Spirit Glyphs: Reimagining Art and Artist in the Work of Chicana Tlamatinime. Modern Fiction Studies, 44 (1), 36-76.

Rebolledo, T. (1995). The Curandera/Bruja: Resolving the Archetype. En Women Singing in the Snow: A Cultural Analysis of Chicana Literature (pp. 83-94). Tucson: University of Arizona Press.

Saldivar-Hull, S. (1999). Introduction to Borderlands/ La Frontera: The New Mestiza. San Francisco: aunt lute books.

Sandoval, C. (2000). Methodology of the Oppressed. Minneapolis: University of Minnesota Press.

Spivak, G. (1988). Can the Subaltern Speak? En C. Nelson \& L. Grossberg (eds.), Marxism and the Interpretation of Culture (pp. 271-313). Chicago: University of Illinois Press.

Superintendent Bans Novel from Colorado School. (s.f). Recuperado de http://www.firstamendmentcenter.org/news. aspx ?id=14785
Todorov, T. (1999). The Conquest of America: The Question of the Other. En R. Howard (trad.). Norman: University of Oklahoma Press.

Torres, M. (1998). Encuentros y Encontronazos: Homeland in the Politics and Identity of the Cuban Diaspora. En A. Darder y R. Torres (eds.), The Latino Studies Reader: Culture, Economy, and Society (pp. 43-62). Malden, Mass.: Blackwell Publishers.

Treviño, C. (2001). Curanderismo in Mexico and Guatemala: Its Historical Evolution from the Sixteenth to the Nineteenth Century. En B. Huber y A. Sandstrom (eds.), Mesoamerican Healers (pp. 47-65). Austin: University of Texas Press.

Turner, B. S. (1997). The Body in Western Society: Social Theory and its Perspectives. En S. Coakley (ed.), Religion and the Body (pp. 15-41). Cambridge, New York: Cambridge University Press.

Vega, M. (2000). Altar of My Soul: The Living Traditions of Santeria. New York: One World.

Walker, B. (1983). The Women's Encyclopedia of Myths and Secrets. Edison, N. J.: Castle Books.

Warner, M. (1983). Alone of All Her Sex: The Myth and the Cult of the Virgin Mary. New York: Vintage Books. 